\title{
Low muscle quality in Japanese type 2 diabetic patients with visceral fat accumulation
}

\author{
Jun Murai ${ }^{1,2}$, Hitoshi Nishizawa ${ }^{1 *} \mathbb{D}$, Akihito Otsuka ${ }^{2}$, Shiro Fukuda ${ }^{1}$, Yoshimitsu Tanaka', Hirofumi Nagao ${ }^{1}$, \\ Yasuna Sakai ${ }^{2}$, Masahide Suzuki ${ }^{2}$, Shinji Yokota ${ }^{2}$, Hidetoshi Tada ${ }^{5}$, Mayumi Doi ${ }^{6}$, Yuya Fujishima', \\ Shunbun Kita ${ }^{1,3}$, Tohru Funahashi ${ }^{1}$, Norikazu Maeda ${ }^{1,4}$, Tadashi Nakamura ${ }^{2}$ and lichiro Shimomura ${ }^{1}$
}

\begin{abstract}
Background: Although obesity-related type 2 diabetes mellitus (T2DM) and sarcopenia in the elderly have been increasing worldwide, the associations among visceral fat accumulation, skeletal muscle indices (mass, strength, and quality) and cardiovascular diseases in T2DM remain poorly investigated.

Methods: We enrolled 183 Japanese T2DM inpatients (126 men, 57 women; mean age 64.7 \pm 12.6 years, \pm SD). The estimated-visceral fat area (eVFA) and skeletal muscle mass were measured by each device using bioelectrical impedance analysis method. We also measured grip strength by dynamometer and motor nerve conduction velocity (MCV). We analyzed the difference in skeletal muscle indices between T2DM patients with and without visceral fat accumulation, and examined the impact of skeletal muscle indices on cardiovascular diseases in patients with visceral fat accumulation.
\end{abstract}

Results: The prevalence of sarcopenia defined by the Consensus of Asian Working Group for Sarcopenia and low skeletal muscle mass were both lower in the visceral fat accumulation (+) group than in (-) group. However, the prevalence of weak hand grip strength was similar in the visceral fat accumulation $(-)$ and (+) groups, indicating that considerable patients with visceral fat accumulation had weak grip strength in spite of fair skeletal muscle mass. Muscle quality [grip strength $(\mathrm{kg}) / \mathrm{arm}$ muscle mass $(\mathrm{kg})$ ] was significantly lower in patients with visceral fat accumulation. Multiple regression analysis identified eVFA, MCV and sex as significant and independent determinants of muscle quality. In visceral fat accumulation (+) group, the patients with low muscle quality had longer duration of diabetes, lower eGFR, higher serum adiponectin, lower MCV and higher prevalence of cardiovascular diseases, compared to the patients with high muscle quality. Finally, sex-and age-adjusted models showed significant association between low muscle quality and cardiovascular diseases in all subjects (odds ratio $2.28, p=0.012$ ), especially in patients with visceral fat accumulation (odds ratio $2.72, \mathrm{p}=0.018$ ).

Conclusions: T2DM patients with visceral fat accumulation had low muscle quality, and patients with low muscle quality were more affected with cardiovascular diseases.

Keywords: Type 2 diabetes, Visceral fat accumulation, Sarcopenia, Skeletal muscle index, Grip strength, Muscle quality, Motor nerve conduction velocity, Cardiovascular disease

\footnotetext{
*Correspondence: hitoshin1127@endmet.med.osaka-u.ac.jp

1 Department of Metabolic Medicine, Graduate School of Medicine,

Osaka University, 2-2 B-5, Yamada-oka, Suita, Osaka 565-0871, Japan

Full list of author information is available at the end of the article
} 


\section{Introduction}

Obesity-related type 2 diabetes mellitus (T2DM) has been increasing worldwide, especially in Asia [1-4]. Asians are more easily susceptible to T2DM despite of relatively low body mass index (BMI), compared to Caucasians [5]. Body fat distribution varied considerably among individuals. Subcutaneous fat accumulation, e.g. high leg fat mass/total fat mass, was associated with decreased cardiovascular diseases [6]. Irrespective of BMI $\left(<25\right.$ or $\left.\geq 25 \mathrm{~kg} / \mathrm{m}^{2}\right)$, visceral fat accumulation, which results from dysregulated eating behavior and physical inactivity, leads to type 2 diabetes mellitus, dyslipidemia, hypertension and atherosclerotic cardiovascular diseases, conceptualized the metabolic syndrome [7].

Prevention of sarcopenia, which is defined as reduction in skeletal muscle mass and strength with aging, is important for improvement in quality of life in the elderly $[8,9]$. Insulin resistance and diabetes mellitus have been reported to be one of risk factors for sarcopenia and exacerbate its pathology [10-13]. On the other hand, it has been reported that grip strength is independently associated with cardiovascular diseases [14, 15]. Collectively, sarcopenia with obesity-related T2DM may be more susceptible to complications of T2DM, such as cardiovascular diseases.

Taken together, it is clinically important for T2DM patients with visceral fat accumulation to evaluate skeletal muscle mass and strength, in addition to fat distribution. However, data have been scarce on visceral fat accumulation and skeletal muscle in T2DM. The present study was designed to investigate the difference in skeletal muscle indices (mass, grip strength and quality) between T2DM patients with and without visceral fat accumulation. The study was also designed to determine the relation between skeletal muscle indices in T2DM patients with visceral fat accumulation and cardiovascular diseases.

\section{Methods \\ Subjects}

The study subjects were consecutive 183 (126 men and 57 women) patients with T2DM admitted to the Division of Diabetes and Endocrinology, Kawasaki Hospital, Kobe, Japan, for poor glycemic control and/or complications, between August 2015 and April 2017. This study was approved by the Human Ethics Committees of Osaka University (no. 15061) and written informed consent was obtained from each subject after explaining the purpose and possible complications of the study. The diagnosis of T2DM was based on the World Health Organization (WHO) National Diabetic Group criteria of 2006 and/or current treatment for diabetes [16]. Patients in whom the visceral fat area (VFA) and/or skeletal muscle mass (see "Clinical examination" below) were not measured were excluded from the study.

\section{Clinical examination}

The duration of diabetes was determined through a medical interview and/or medical records. Height $(\mathrm{cm})$, body weight $(\mathrm{kg})$, waist circumference (WC) at the level of the umbilicus $(\mathrm{cm})$, and grip strength $(\mathrm{kg})$ were measured in the standing position on admission to the hospital. Grip strength was measured using an isokinetic dynamometer (Smedley's Hand Dynamometer) on the right and left hand and then the average was calculated.

The VFA was estimated by bioelectrical impedance analysis (BIA) method using EW-FA90 (Panasonic Corporation). The VFA measured by the BIA method correlates significantly with that determined by computed tomography, which is the golden standard method for measurement of VFA [17]. In the present study, the muscle masses of the arms and legs, and trunk were measured by In Body 720 (InBody Japan Inc.), which is applied by BIA method. The measured values of muscle mass by the BIA method also correlate with those measured by dual-energy X-ray absorptiometry (DXA) [18]. The arm muscle quality represented the ratio of grip strength to the entire arm muscle mass in kilograms [grip strength $(\mathrm{kg}) / \mathrm{arm}$ muscle mass (kg)] [19] (measured on both sides and then averages).

Systolic/diastolic blood pressure (BP) was measured with a standard mercury sphygmomanometer on the right and left arms in supine position after at least 10-min rest, and the average was calculated. Venous blood samples were collected in the morning after overnight fasting for measurements of glucose and HbA1c [National Glycohemoglobin Standardization Program (NGSP)], serum C-peptide, alanine transaminase (ALT), uric acid (UA), high-density lipoprotein cholesterol (HDL-C), triglyceride (TG), low-density lipoprotein cholesterol (LDL-C), creatinine, high-sensitivity CRP (hs-CRP), and brain natriuretic peptide (BNP). The estimated glomerular filtration rate (eGFR) was calculated by using the following formula: [eGFR $=194 \times($ serum creatinine $\left.{ }^{-1.094}\right) \times\left(\mathrm{age}^{-0.287}\right) \times \mathrm{F} \quad$ (male, $\mathrm{F}=1 ;$ female, $\mathrm{F}=0.739)]$ [20]. Serum levels of total adiponectin were measured by enzyme-linked immunosorbent assay (ELISA) (human adiponectin ELISA kit, Otsuka Pharmaceutical Co. Tokushima, Japan), as reported previously [21].

The maximum intima-media thickness (IMT) of the common carotid artery (CCA) was measured in supine position by echography, as described previously [22, 23]. Arterial stiffness was assessed by measuring brachial-ankle pulse wave velocity (baPWV), ankle-brachial 
index (ABI), using an automatic wave form analyzer (BP203RPE III, FUKUDA COLIN Co, Japan).

\section{Nerve conduction velocity}

To measure motor nerve conduction velocity (MCV), a nerve conduction study (NCS) was performed using standard electrodiagnostic equipment (Neuropack2 MEB-7202, Nihon Koden, Japan) in a temperature controlled room at the Department of Physiology, Kawasaki Hospital. The preparation and equipment settings followed standard protocols [24]. In each patient, the MCV was measured by recording median nerve $(\mathrm{MN})$ activity by supramaximal stimulation of the $\mathrm{MN}$ at the proximal site (antecubital fossa) and the distal site (wrist) on each arm [25], and then the average was calculated.

\section{Definitions}

According to the Consensus of Asian Working Group for Sarcopenia (AWGS) [9], weak grip strength was defined as $<26 \mathrm{~kg}$ for men and $<18 \mathrm{~kg}$ for women. Skeletal muscle index (SMI) was defined as height-adjusted appendicular skeletal muscle mass: muscle mass of the arms and legs/ height $\mathrm{t}^{2}\left(\mathrm{~kg} / \mathrm{m}^{2}\right)$, based on the definition recommended by AWGS. Low skeletal muscle mass was defined as $\mathrm{SMI}<7.0 \mathrm{~kg} / \mathrm{m}^{2}$ for men and $<5.7 \mathrm{~kg} / \mathrm{m}^{2}$ for women as measured by BIA. Sarcopenia was defined as weak grip strength and low skeletal muscle mass.

Visceral fat accumulation was defined as estimated VFA (eVFA) of $\geq 100 \mathrm{~cm}^{2}$, according to the guideline of Japan Society for the Study of Obesity [26, 27]. Hypertension was defined by systolic $\mathrm{BP} \geq 140 \mathrm{mmHg}$ and/or diastolic $\mathrm{BP} \geq 90 \mathrm{mmHg}$. Dyslipidemia was defined as low-density lipoprotein cholesterol (LDL-C) concentration $\geq 140 \mathrm{mg} /$ $\mathrm{dl}$, triglyceride (TG) concentration $\geq 150 \mathrm{mg} / \mathrm{dl}$, and/or high-density lipoprotein cholesterol (HDL-C) concentration $<40 \mathrm{mg} / \mathrm{dl}$. Hyperuricemia was defined as serum uric acid (UA) concentration $\geq 7.0 \mathrm{mg} / \mathrm{dl}$ according to the Japanese criteria [28]. Patients were also considered positive for hypertension and/or dyslipidemia and/or hyperuricemia if they received antihypertensive, and/or anti-dyslipidemic, and/or anti-hyperuricemic medications respectively. Fatty liver was defined as presence of liver-to-kidney contrast and/or deep beam attenuation, using abdominal ultrasonography (Aplio MX Diagnostic Ultrasound System SSA780A, Toshiba Medical Systems Inc.) [29]. Cardiovascular disease (CVD) was defined as coronary artery disease (CAD) and/or cerebrovascular disease and/or peripheral arterial disease (PAD). CAD was defined as significant coronary stenosis(es) by coronary angiography or computed tomography, and/ or positive ischemia by stress myocardial scintigraphy. Cerebrovascular disease was defined as history of stroke by a medical interview and/or old cerebral infarction by magnetic resonance imaging (MRI). PAD was defined as ankle-brachial index $(\mathrm{ABI}) \leq 0.9$ or performance of a revascularization procedure or amputation of lower extremity because of PAD [30,31].

\section{Statistical analysis}

Data are presented as mean \pm SD or median (interquartile range). In all cases, probability ( $p$ ) value of $<0.05$ was considered statistically significant. The unpaired $t$ test was used to determine differences in various parameters between two groups. Frequencies were compared between two groups by Fisher's exact test. The correlations between muscle quality and other parameters were first analyzed by simple linear regression analysis and then by multiple regression analysis (Tables 2,3 ). To clarify clinical features of patients with visceral fat accumulation with low muscle quality, the subjects were classified into four groups based on visceral fat accumulation and muscle quality; the low group $<10.3(\mathrm{~kg} / \mathrm{kg})$, which is the median value of muscle quality, and the high group $\geq 10.3$ $(\mathrm{kg} / \mathrm{kg})$ (Table 4). The associations between muscle quality/grip strength and prevalence of CVD were assessed by logistic regression analysis (Table 5 , Additional file 1 : Tables S2, S3). Models that examined CVD as the outcome included adjustments for the following covariates: sex, age, sex and age. All analyses were performed with the JMP Pro 10.0.2 software for Windows (SAS Institute, Cary, NC).

\section{Results}

Prevalence of low skeletal muscle mass, weak grip strength, and sarcopenia

We enrolled 183 Japanese patients in this study [126 men and 57 women; age $64.7 \pm 12.6$ years; range, $33-88$ years, BMI $25.3 \pm 4.7 \mathrm{~kg} / \mathrm{m}^{2}$, WC; males $93.1 \pm 13.0 \mathrm{~cm}$, females $95.3 \pm 12.8 \mathrm{~cm}$, eVFA; males $145.2 \pm 60.0 \mathrm{~cm}^{2}$, females $121.0 \pm 49.2 \mathrm{~cm}^{2}$ ] (Table 1). Among the total, 57 cases (31\%) had low skeletal muscle mass, as measured by BIA (SMI, men: $<7.0$, women: $<5.7 \mathrm{~kg} / \mathrm{m}^{2}$ ), and 104 cases (57\%) had weak grip strength (men: $<26 \mathrm{~kg}$, women: $<18 \mathrm{~kg}$ ). Accordingly, $41(22 \%)$ T2DM patients were diagnosed with sarcopenia. In sex-specific analyses, 40 cases (32\%) in men and 17 cases (30\%) in women had low skeletal muscle mass, and 60 cases (48\%) in men and 44 cases $(77 \%)$ in women had weak grip strength. Then, 26 cases (21\%) in men and 15 cases (26\%) in women were diagnosed with sarcopenia.

Next, we divided the patients into two groups; patients with and those without visceral fat accumulation, and examined the prevalence of sarcopenia and its related factors (Fig. 1). Sarcopenia was observed in 14\% (18/129) of visceral accumulation (+) group and 43\% (23/54) of visceral accumulation $(-)$ group $(\mathrm{p}<0.001)$ (Fig. 1a). Low 
Table 1 Clinical characteristics of study subjects

\begin{tabular}{|c|c|}
\hline n (males/females) & $183(126 / 57)$ \\
\hline Age (years) & $64.7 \pm 12.6$ \\
\hline Duration of diabetes (years) & $9(3-21)$ \\
\hline BMI $\left(\mathrm{kg} / \mathrm{m}^{2}\right)$ & $25.3 \pm 4.7$ \\
\hline WC (cm) & $93.8 \pm 12.9$ \\
\hline Males & $93.1 \pm 13.0$ \\
\hline Females & $95.2 \pm 12.8$ \\
\hline eVFA $\left(\mathrm{cm}^{2}\right)$ & $137.7 \pm 57.8$ \\
\hline Males & $145.2 \pm 60.0$ \\
\hline Females & $121.0 \pm 49.2$ \\
\hline Grip strength (kg) & $23.5 \pm 9.5$ \\
\hline Males & $27.5 \pm 8.1$ \\
\hline Females & $14.8 \pm 6.1$ \\
\hline Skeletal mass index $\left(\mathrm{kg} / \mathrm{m}^{2}\right)$ & $7.1 \pm 1.2$ \\
\hline Males & $7.5 \pm 1.0$ \\
\hline Females & $6.1 \pm 1.1$ \\
\hline Systolic BP (mmHg) & $131.7 \pm 19.3$ \\
\hline Diastolic BP (mmHg) & $76.4 \pm 12.0$ \\
\hline $\mathrm{HbA1c}(\%)$ & $9.5 \pm 2.1$ \\
\hline Serum C-peptide (ng/ml) & $1.8 \pm 1.3$ \\
\hline $\operatorname{ALT}(U / I)$ & $31.2 \pm 31.1$ \\
\hline UA (mg/dl) & $5.3 \pm 1.6$ \\
\hline eGFR (ml/min) & $67.3 \pm 28.3$ \\
\hline $\mathrm{HDL}-\mathrm{C}(\mathrm{mg} / \mathrm{dl})$ & $46.1 \pm 16.8$ \\
\hline TG (mg/dl) & $148(105-217)$ \\
\hline LDL-C (mg/dl) & $106.5 \pm 36.8$ \\
\hline $\mathrm{hs}-\mathrm{CRP}(\mathrm{mg} / \mathrm{dl})$ & $0.12(0.06-0.35)$ \\
\hline Adiponectin $(\mu \mathrm{g} / \mathrm{ml})$ & $7.3(4.6-11.3)$ \\
\hline BNP $(p g / m l)$ & $15.7(7.7-35.3)$ \\
\hline CCA max IMT (mm) & $0.9 \pm 0.5$ \\
\hline PWV (m/s) & $1810 \pm 379$ \\
\hline $\mathrm{MCV}(\mathrm{m} / \mathrm{s})$ & $49.5 \pm 4.4$ \\
\hline Hypertension & $68 \%$ \\
\hline Hyperuricemia & $26 \%$ \\
\hline Dyslipidemia & $86 \%$ \\
\hline Fatty liver & $58 \%(105 / 180)$ \\
\hline Cardiovascular disease & $34 \%$ \\
\hline
\end{tabular}

Data are presented as mean $\pm S D$, or median (interquartile range), or frequency $\%$ (number of subjects)

$B M I$ body mass index, WC waist circumference, eVFA estimated visceral fat area, $B P$ blood pressure, $A L T$ alanine transaminase, UA uric acid, eGFR estimated glomerular filtration rate, $H D L-C H D L$ cholesterol, $T G$ triglyceride, $L D L-C L D L$ cholesterol, $h s-C R P$ high sensitive $C$-reactive protein, $B N P$ brain natriuretic peptide, CCA common carotid artery, IMT intima-media thickness, $P W V$ pulse wave velocity, $M C V$ motor nerve conduction velocity

skeletal muscle mass diagnosed by low SMI was observed in $19 \%(25 / 129)$ of visceral accumulation $(+)$ group and in $59 \%(32 / 54)$ of $(-)$ group $(\mathrm{p}<0.001)$ (Fig. 1b). The prevalence of sarcopenia and low skeletal muscle mass were both lesser in (+) group than in (-) group (Fig. 1a, b). On the other hand, the prevalence of weak hand grip strength was not different between the two groups [63\% $(34 / 54)$ in (-) group, and 54\% (70/129) in (+) group] (Fig. 1c). In sex-specific analyses, almost the same data were observed both in men and in women (Additional file 1: Figure S1). These data suggest that patients with visceral fat accumulation tended to have weak hand grip strength in spite of fair skeletal muscle mass.

Then, we focused on muscle quality, which is defined as muscle strength divided by skeletal muscle mass [19]. As shown in Fig. 2, the muscle quality was significantly lower in patients with visceral fat accumulation than those without. In sex-specific analyses, the muscle quality was significantly lower in patients with visceral fat accumulation both in men and in women (Additional file 1: Figure S2). Additional file 1: Table S1 provides more details on skeletal muscle indices. Although all indices of muscle mass were clearly larger in patients with visceral fat accumulation, grip strength was not significantly different in both males and females.

\section{Clinical parameters associated with muscle quality}

Simple linear regression analysis showed significant relationships between muscle quality and age, duration of diabetes, BMI, eVFA, eGFR, LDL-C, CCA max IMT, PWV, and MCV (Table 2). Sex difference was observed in muscle quality (men $10.6 \pm 2.7$ vs women $8.6 \pm 3.1$, $\mathrm{p}<0.001$ ). Then, multiple regression analysis which included age, sex, duration of diabetes, eVFA, eGFR, LDL-C, CCA max IMT, MCV identified sex, eVFA and $\mathrm{MCV}$ as significant explanatory variables associated with muscle quality (Table 3).

\section{Clinical features of T2DM patients with visceral fat accumulation and low muscle quality}

Based on the above results, we focused on the clinical features of patients with both visceral fat accumulation and low muscle quality. The subjects were classified into four groups based on the eVFA and muscle quality (Table 4). In visceral fat accumulation $(+)$ group, the patients with low muscle quality had longer duration of diabetes, lower eGFR, higher serum adiponectin, and lower MCV, compared to the patients with high muscle quality. No significant differences were observed in the prevalence of hypertension, hyperuricemia, dyslipidemia and fatty liver between the two groups. Interestingly, the prevalence of atherosclerotic cardiovascular diseases was clearly higher in the low muscle quality group with visceral fat accumulation; 10 cases (18\%) of the high muscle quality group, versus 30 cases (41\%) of the low muscle quality group of subjects with visceral fat accumulation $(\mathrm{p}=0.007)($ Table 4$)$. 


\section{a Sarcopenia}

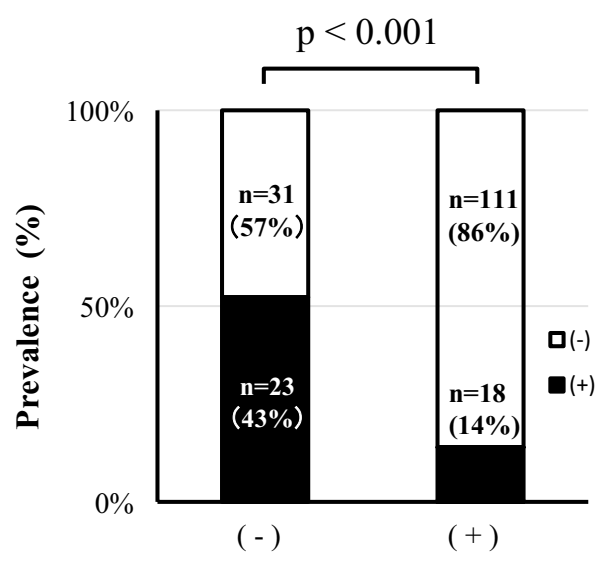

Visceral fat accumulation

b Low SMI

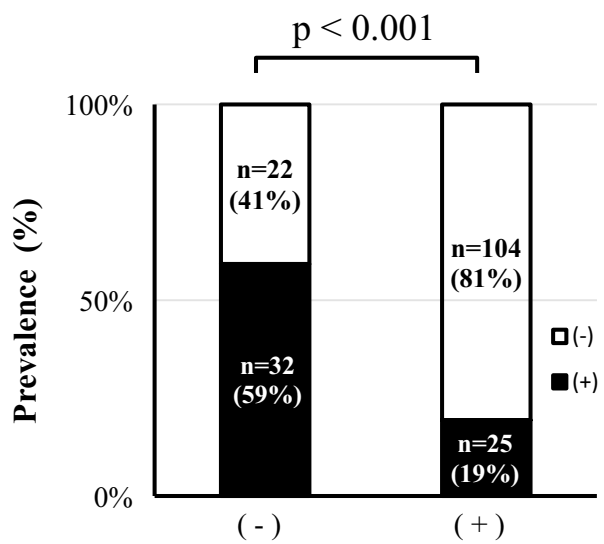

Visceral fat accumulation
C Weak grip strength

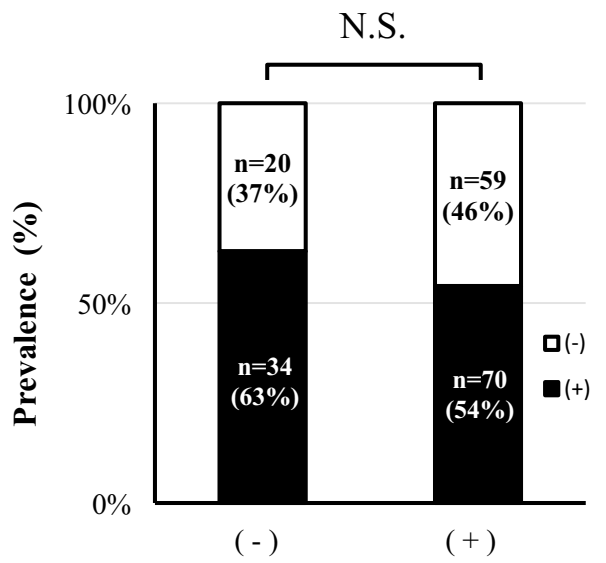

Visceral fat accumulation

Fig. 1 Visceral fat accumulation and prevalence of sarcopenia, low skeletal muscle mass, and weak grip strength. The subjects were divided into two groups: visceral fat accumulation (-) group and visceral fat accumulation (+) group. Visceral fat accumulation was defined as eVFA $\geq 100 \mathrm{~cm}{ }^{2}$. $p$ value by Fischer's exact test. SMI skeletal muscle index = appendicular skeletal muscle mass/height ${ }^{2}\left(\mathrm{~kg} / \mathrm{m}^{2}\right)$. Definition of sarcopenia, low skeletal muscle mass and weak grip strength are described in "Methods" section. NS not significant

\section{Association of low muscle quality with atherosclerotic cardiovascular diseases}

We next investigated the impact of lower muscle quality on cardiovascular diseases using logistic regression analysis (Table 5). In the sex- and age-adjusted models, lower muscle quality was significantly associated with cardiovascular diseases in overall subjects (odds ratio 2.28, $\mathrm{p}=0.012$ ). However, there was no significant difference in the associations between lower muscle quality and cardiovascular diseases in sex- and age-adjusted models subjects without visceral fat accumulation $(p=0.134)$. Interestingly, in patients with visceral fat accumulation, the association of lower muscle quality with cardiovascular diseases was significant as higher odds ratio in sex- and age- adjusted models (odds ratio 2.72, $\mathrm{p}=0.018$ ). In male subjects only, significant associations of lower muscle quality with cardiovascular disease were observed in overall patients and patients with visceral fat accumulation (odds ratio 2.59, $\mathrm{p}=0.020$, odds ratio $4.60, \mathrm{p}=0.006$, respectively), but not in patients without visceral fat accumulation, in the age-adjusted models (Additional file 1: Table S2). Finally, we examined the association of hand grip strength with cardiovascular diseases. There were significant associations of weak grip strength with 


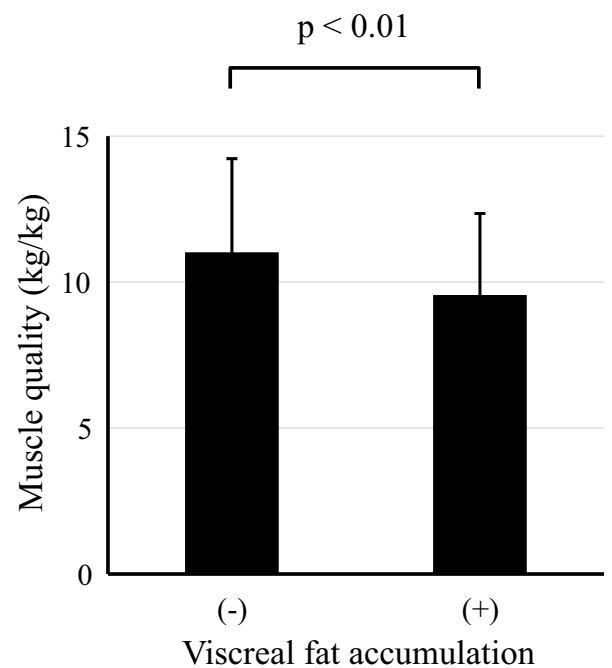

Fig. 2 Visceral fat accumulation and muscle quality (grip strength/ arm skeletal muscle mass). The subjects were divided into two groups: visceral fat accumulation (-) group and visceral fat accumulation (+) group. Visceral fat accumulation was defined as estimated visceral fat area $\geq 100 \mathrm{~cm}^{2}$. Muscle quality was defined as muscle strength divided by skeletal muscle mass [grip strength (kg)/ arm muscle mass $(\mathrm{kg})]$. $p$ value by unpaired $t$ test

Table 2 Simple regression analyses of the factors associated with muscle quality

\begin{tabular}{|c|c|c|}
\hline & \multicolumn{2}{|c|}{$\begin{array}{l}\text { Simple linear regression } \\
\text { model }\end{array}$} \\
\hline & $r$ & $p$ value \\
\hline Age (years) & -0.185 & 0.012 \\
\hline Duration of diabetes (years) & -0.191 & 0.018 \\
\hline BMI $\left(\mathrm{kg} / \mathrm{m}^{2}\right)$ & -0.350 & $<0.001$ \\
\hline eVFA $\left(\mathrm{cm}^{2}\right)$ & -0.266 & $<0.001$ \\
\hline Systolic BP (mmHg) & -0.062 & 0.407 \\
\hline Diastolic BP (mmHg) & 0.085 & 0.255 \\
\hline $\mathrm{HbA1c}(\%)$ & 0.103 & 0.173 \\
\hline Serum C-peptide (ng/ml) & -0.126 & 0.091 \\
\hline $\operatorname{ALT}(U / I)$ & 0.062 & 0.404 \\
\hline $\mathrm{UA}(\mathrm{mg} / \mathrm{dl})$ & -0.002 & 0.981 \\
\hline eGFR (ml/min) & 0.245 & 0.001 \\
\hline $\mathrm{HDL}-\mathrm{C}(\mathrm{mg} / \mathrm{dl})$ & 0.129 & 0.081 \\
\hline $\mathrm{TG}(\mathrm{mg} / \mathrm{dl})$ & 0.120 & 0.105 \\
\hline LDL-C (mg/dl) & 0.204 & 0.006 \\
\hline hs-CRP (mg/dl) & -0.097 & 0.205 \\
\hline Adiponectin ( $\mu \mathrm{g} / \mathrm{ml})$ & -0.071 & 0.341 \\
\hline $\operatorname{BNP}(p g / m l)$ & 0.088 & 0.242 \\
\hline CCA max IMT (mm) & -0.159 & 0.044 \\
\hline $\mathrm{PWV}(\mathrm{m} / \mathrm{s})$ & -0.196 & 0.009 \\
\hline $\mathrm{MCV}(\mathrm{m} / \mathrm{s})$ & 0.303 & $<0.001$ \\
\hline
\end{tabular}

Table 3 Multiple regression analysis of the factors associated with muscle quality

\begin{tabular}{lcr}
\hline & \multicolumn{2}{c}{ Multiple regression } \\
\cline { 2 - 3 } & \multicolumn{1}{c}{ Std $\boldsymbol{\beta}$} & $\boldsymbol{p}$ value \\
\hline Age (years) & -0.048 & 0.599 \\
Sex & 0.405 & $<0.001$ \\
Duration of diabetes (years) & -0.094 & 0.270 \\
eVFA $\left(\mathrm{cm}^{2}\right)$ & -0.348 & $<0.001$ \\
eGFR $(\mathrm{ml} / \mathrm{min})$ & -0.085 & 0.320 \\
LDL-C $(\mathrm{mg} / \mathrm{dl})$ & 0.081 & 0.270 \\
CCA max IMT (mm) & -0.116 & 0.120 \\
PWV $(\mathrm{m} / \mathrm{s})$ & -0.127 & 0.140 \\
MCV $(\mathrm{m} / \mathrm{s})$ & 0.301 & $<0.001$ \\
\hline
\end{tabular}

cardiovascular diseases in overall patients with/without visceral fat accumulation (Additional file 1: Table S3).

\section{Discussion}

Sarcopenia and skeletal muscle indices in type 2 diabetic patients with visceral fat accumulation

In the present study, sarcopenia was detected in $22 \%$ of the hospitalized patients with T2DM (age $64.7 \pm 12.6$ years; range 33-88 years). Since the reported prevalence of sarcopenia is $1-29 \%$ in community-dwelling populations [32] and 7.5-8.2\% in Japanese population aged over 60 or 65 years [33, 34], the prevalence of sarcopenia in our study of T2DM is relatively higher than in the general population. These results confirm the previous findings that T2DM patients are susceptible to sarcopenia $[35,36]$.

First, we focused on visceral fat accumulation in T2DM. The prevalence of sarcopenia and low skeletal muscle mass were both lower in patients with visceral fat accumulation (Fig. 1a, b), probably reflecting relative larger amount of muscle mass due to overweight. On the other hand, the prevalence of weak hand grip strength was not influenced by the amount of visceral fat (Fig. 1c), indicating that considerable patients with visceral fat accumulation had weak hand grip strength despite fair skeletal muscle mass. It was recently reported that the patients with decreased grip strength and abdominal obesity were at higher risk of worsening disability [37].

Low muscle quality in type 2 diabetic patients with visceral fat accumulation, and its association with cardiovascular diseases

Then, we focused on muscle quality. As shown in Fig. 2, muscle quality of patients with visceral fat accumulation was significantly lower than in those without. 
Table 4 Clinical features of type 2 diabetic patients with visceral fat accumulation and low muscle quality

\begin{tabular}{|c|c|c|c|c|c|c|}
\hline & \multicolumn{3}{|c|}{ Visceral fat accumulation (-) group } & \multicolumn{3}{|c|}{ Visceral fat accumulation $(+)$ group } \\
\hline & \multicolumn{2}{|l|}{ Muscle quality } & \multirow[t]{2}{*}{$p$ value } & \multicolumn{2}{|l|}{ Muscle quality } & \multirow[t]{2}{*}{$p$ value } \\
\hline & High group & Low group & & High group & Low group & \\
\hline n (males/females) & $36(25 / 11)$ & $18(8 / 10)$ & $0.087^{\mathrm{a}}$ & $56(46 / 10)$ & $73(47 / 26)$ & $0.030^{\mathrm{a}}$ \\
\hline Age (years) & $65.5 \pm 11.4$ & $74.3 \pm 7.7$ & 0.005 & $61.4 \pm 13.3$ & $64.4 \pm 12.5$ & 0.192 \\
\hline Duration of diabetes (years) & $5(0-30)$ & $20(8-29)$ & 0.344 & $5(1-13)$ & $12(6-21)$ & 0.007 \\
\hline BMI $\left(\mathrm{kg} / \mathrm{m}^{2}\right)$ & $20.0 \pm 2.4$ & $21.5 \pm 2.7$ & 0.040 & $26.5 \pm 3.8$ & $27.9 \pm 4.0$ & 0.042 \\
\hline WC (cm) & $79.3 \pm 6.7$ & $83.3 \pm 8.5$ & 0.066 & $97.8 \pm 10.3$ & $100.5 \pm 10.5$ & 0.125 \\
\hline eVFA $\left(\mathrm{cm}^{2}\right)$ & $63.3 \pm 21.7$ & $75.1 \pm 21.5$ & 0.067 & $164.8 \pm 39.7$ & $168.9 \pm 40.0$ & 0.565 \\
\hline Grip strength (kg) & $24.8 \pm 7.7$ & $13.4 \pm 5.4$ & $<0.001$ & $30.9 \pm 8.0$ & $20.0 \pm 7.8$ & $<0.001$ \\
\hline Skeletal mass index $\left(\mathrm{kg} / \mathrm{m}^{2}\right)$ & $6.3 \pm 0.9$ & $6.0 \pm 0.9$ & 0.213 & $7.4 \pm 0.9$ & $7.4 \pm 1.2$ & 0.945 \\
\hline Systolic BP (mmHg) & $131.7 \pm 24.1$ & $140.0 \pm 22.2$ & 0.224 & $130.2 \pm 15.3$ & $130.9 \pm 18.6$ & 0.831 \\
\hline Diastolic BP (mmHg) & $77.0 \pm 11.5$ & $72.9 \pm 9.4$ & 0.196 & $77.8 \pm 11.0$ & $76.0 \pm 13.4$ & 0.414 \\
\hline $\mathrm{HbA1c}(\%)$ & $9.6 \pm 2.2$ & $10.1 \pm 3.5$ & 0.605 & $9.9 \pm 1.9$ & $9.2 \pm 1.7$ & 0.032 \\
\hline Serum C-peptide (ng/ml) & $1.2 \pm 0.8$ & $1.9 \pm 1.8$ & 0.058 & $2.0 \pm 1.4$ & $1.9 \pm 1.2$ & 0.679 \\
\hline ALT (U/I) & $29.2 \pm 37.6$ & $21.1 \pm 12.8$ & 0.380 & $35.2 \pm 26.3$ & $31.5 \pm 33.8$ & 0.580 \\
\hline UA (mg/dl) & $4.5 \pm 1.6$ & $5.0 \pm 1.6$ & 0.355 & $5.6 \pm 1.3$ & $5.4 \pm 1.6$ & 0.394 \\
\hline eGFR (ml/min) & $76.8 \pm 31.9$ & $57.0 \pm 26.5$ & 0.027 & $72.9 \pm 26.0$ & $61.1 \pm 26.6$ & 0.016 \\
\hline $\mathrm{HDL}-\mathrm{C}(\mathrm{mg} / \mathrm{dl})$ & $57.3 \pm 23.1$ & $47.9 \pm 17.4$ & 0.135 & $45.0 \pm 13.3$ & $41.1 \pm 12.5$ & 0.090 \\
\hline $\mathrm{TG}(\mathrm{mg} / \mathrm{dl})$ & $123(82-173)$ & $116(82-167)$ & 0.890 & $187(127-267)$ & $152(113-213)$ & 0.077 \\
\hline LDL-C (mg/dl) & $101.7 \pm 33.9$ & $91.1 \pm 38.5$ & 0.306 & $119.4 \pm 38.3$ & $102.7 \pm 34.4$ & 0.011 \\
\hline hs-CRP (mg/dl) & $0.1(0.0-0.2)$ & $0.2(0.1-0.6)$ & 0.153 & $0.1(0.1-0.4)$ & $0.1(0.1-0.4)$ & 0.301 \\
\hline Adiponectin ( $\mu \mathrm{g} / \mathrm{ml})$ & $11.3(7.3-16.9)$ & $8.2(6.5-15.7)$ & 0.878 & $5.3(3.7-8.2)$ & $6.6(4.8-10.6)$ & 0.009 \\
\hline $\mathrm{BNP}(\mathrm{pg} / \mathrm{ml})$ & $22.4(15.0-59.5)$ & $28.0(15.1-49.9)$ & 0.302 & $10.7(4.9-21.7)$ & $16.4(8.1-29.8)$ & 0.726 \\
\hline CCA max IMT (mm) & $0.8 \pm 0.4$ & $1.3 \pm 0.8$ & 0.013 & $0.9 \pm 0.4$ & $0.9 \pm 0.4$ & 0.505 \\
\hline $\mathrm{PWV}(\mathrm{m} / \mathrm{s})$ & $1791 \pm 463$ & $2051 \pm 370$ & 0.054 & $1744 \pm 329$ & $1814 \pm 358$ & 0.262 \\
\hline $\mathrm{MCV}(\mathrm{m} / \mathrm{s})$ & $50.2 \pm 3.7$ & $48.3 \pm 4.1$ & 0.100 & $50.8 \pm 3.9$ & $48.5 \pm 4.9$ & 0.003 \\
\hline Hypertension & $58 \%$ & $72 \%$ & $0.382^{\mathrm{a}}$ & $64 \%$ & $75 \%$ & $0.180^{a}$ \\
\hline Hyperuricemia & $17 \%$ & $17 \%$ & $1.000^{\mathrm{a}}$ & $30 \%$ & $30 \%$ & $1.000^{a}$ \\
\hline Dyslipidemia & $72 \%$ & $89 \%$ & $0.298^{\mathrm{a}}$ & $91 \%$ & $89 \%$ & $0.775^{\mathrm{a}}$ \\
\hline Fatty liver & $33 \%$ & $28 \%$ & $0.764^{\mathrm{a}}$ & $76 \%(41 / 54)$ & $65 \%(47 / 72)$ & $0.241^{a}$ \\
\hline Cardiovascular disease & $33 \%$ & $61 \%$ & $0.080^{\mathrm{a}}$ & $18 \%$ & $41 \%$ & $0.007^{\mathrm{a}}$ \\
\hline
\end{tabular}

Data are expressed as mean $\pm S D$, or median (interquartile range), or frequency \% (number of subjects). Unpaired t test was used between low muscle quality group vs high muscle quality group

${ }^{a}$ Fisher's exact test (low muscle quality group vs high muscle quality group)

Interestingly, multiple regression analysis identified eVFA and MCV as significant determinants of muscle quality (Table 3). Previous studies reported lower muscle quality in T2DM, compared with subjects without diabetes, and was associated with the duration of diabetes [19]. Collectively, these results suggest that visceral fat accumulation and/or neuropathy per se can be associated with muscle quality in T2DM. Our results also showed that low muscle quality had significant impact on cardiovascular diseases in both the sex- and age-adjusted models (Table 5 and Additional file 1: Table S2), suggesting that T2DM patients with visceral fat accumulation and low muscle quality could be at higher risk of atherosclerotic cardiovascular diseases.
The reported mechanism(s) of decreased muscle strength in diabetes include insulin resistance [12], insulin signaling [38], neuropathy [39], and hyperglycemia [19]. Since MCV correlated significantly with muscle quality (Tables 2, 3), it is possible that neuropathic changes could be involved in the decrease of muscle strength through motoneurons dysfunction.

The exact etiology of cardiovascular diseases and decreased muscle quality in T2DM with visceral fat accumulation is unknown. Dysregulation of adipocytokines/adipokines, such as hypoadiponectinemia, has been reported previously [40], and the high levels of inflammatory cytokines in the accumulated visceral fat could result in systemic low-grade inflammation, insulin 
Table 5 Association of low muscle quality for cardiovascular disease in type 2 diabetic patients

\begin{tabular}{lll}
\hline & Odds ratio & $\boldsymbol{p}$ value \\
\hline All & & \\
Not adjusted & $2.61(1.40-4.97)$ & 0.003 \\
Sex adjusted & $2.40(1.27-4.62)$ & 0.007 \\
Age adjusted & $2.42(1.28-4.66)$ & 0.006 \\
Sex, age adjusted & $2.28(1.20-4.42)$ & 0.012 \\
eVFA $<100 \mathrm{~cm}^{2}$ & & \\
Not adjusted & $3.14(0.99-10.61)$ & 0.052 \\
Sex adjusted & $3.39(1.03-12.27)$ & 0.045 \\
Age adjusted & $2.43(0.70-8.81)$ & 0.162 \\
Sex, age adjusted & $2.64(0.74-10.05)$ & 0.134 \\
eVFA $\geq 100 \mathrm{~cm}^{2}$ & & \\
Not adjusted & $3.21(1.44-7.64)$ & 0.004 \\
Sex adjusted & $2.83(1.24-6.83)$ & 0.013 \\
Age adjusted & $3.05(1.36-7.31)$ & 0.007 \\
Sex, age adjusted & $2.72(1.19-6.61)$ & 0.018 \\
\hline
\end{tabular}

resistance, microalbuminuria [41, 42], arterial stiffness [43], and atherosclerotic cardiovascular diseases [40, 44]. In fact, hypercytokinemia, including high serum levels of tumor necrosis factor- $\alpha$ and interleukin 6 (IL-6), has been reported to be associated with both muscle mass and muscle strength in the elderly $[45,46]$. Moreover, it was reported that subjects with abdominal obesity and sarcopenia had high plasma levels of IL-6 [47]. Accumulation of visceral fat had a significant impact on the gene expression profile in peripheral blood cells [48], and also on muscle-derived bioactive molecules called myokines $[47,49]$. Systemic inflammation and dysregulation of adipocytokines in visceral fat accumulation might be associated with decreased muscle quality and atherosclerosis. We have recently reported that adiponectin is associated with skeletal muscle via T-cadherin [50]. Although it is well known that adiponectin acts as an insulin-sensitizer in skeletal muscles [51], its effects on skeletal muscle mass and strength remain elusive.

It has been reported that grip strength is inversely associated with mortality $[14,52]$. In the present study, grip strength correlated significantly with cardiovascular diseases (Additional file 1: Table S3). However, $20 \%(n=16$, $54.7 \pm 11.6$ years) of patients without weak grip strength $(\mathrm{n}=79,58.0 \pm 12.3$ years $)$ had lower muscle quality $[<10.3(\mathrm{~kg} / \mathrm{kg})]$. Since considerable number of overweight subjects have relatively larger muscle and increased total fat mass, it may not be appropriate to use absolute values of muscle strength in the analysis. Accordingly, we need to evaluate muscle strength per muscle mass, i.e., muscle quality, particularly in subjects with visceral fat accumulation. On the other hand, in patients without visceral fat accumulation, grip strength correlated significantly with cardiovascular diseases (Additional file 1: Table S3), suggesting that it is important to evaluate the absolute value of grip strength especially in patients free of visceral fat accumulation. In male patients, lower muscle quality was also associated with cardiovascular diseases (Additional file 1: Table S2). However, due to the limited number, analyses of female patients could not be performed.

Recently, it was reported that skeletal muscle indices were positively correlated with C-peptide, which showed endogenous insulin reserve [53], and dipeptidyl peptidase 4 inhibitors attenuated the decline of skeletal muscle in patients with T2DM [54]. Taken together, the present results demonstrated the importance of evaluating muscle quality in type 2 diabetic patients with visceral fat accumulation for potential risk assessment for atherosclerosis, suggesting that physicians might be better to consider selection of anti-diabetic agent from view point of the effect on skeletal muscle and support for patients in modifying their exercise habit.

Our study was cross-sectional in design conducted in a single medical facility and could thus only examine associations among visceral fat accumulation, muscle quality, and cardiovascular diseases. For any causal relationship, larger cohort and prospective studies are needed. In the present study, the methods of measurement for VFA and skeletal muscle mass were BIA methods (EW-FA90 and In Body 720, respectively) as alternatives of CT method and DXA method, respectively.

\section{Conclusion}

Our study demonstrated that patients with T2DM and visceral fat accumulation had lower muscle quality, and that patients with low muscle quality were more affected with cardiovascular diseases.

\section{Additional file}

Additional file 1: Figure S1. Visceral fat accumulation and prevalence of sarcopenia, low skeletal muscle mass, and weak grip strength (men, women). The subjects were divided into two groups: visceral fat accumulation (-) group and visceral fat accumulation (+) group. p value by Fischer's exact test. NS: not significant. Figure S2. Visceral fat accumulation and muscle quality (men, women). The male and female subjects were divided into two groups: visceral fat accumulation (-) group and visceral fat accumulation (+) group. $p$ value by unpaired t test. Table S1. Skeletal muscle indices of type 2 diabetic patients with visceral fat accumulation. Table S2. Association of low muscle quality for cardiovascular disease in type 2 diabetic patients (men). Table S3. Association of weak grip strength for cardiovascular disease in type 2 diabetic patients.

\section{Abbreviations}

ALT: alanine transaminase; BMI: body mass index; BP: blood pressure; BNP: brain natriuretic peptide; CCA: common carotid artery; eVFA: estimated visceral fat area; eGFR: estimated glomerular filtration rate; HDL-C: HDL cholesterol; hs-CRP: high sensitive C-reactive protein; IL-6: interleukin 6; IMT: intima-media thickness; LDL-C: LDL cholesterol; MCV: motor nerve conduction 
velocity; PWV: pulse wave velocity; SMl: skeletal mass index; TG: triglyceride; UA: uric acid; VFA: visceral fat area; WC: waist circumference.

\section{Authors' contributions}

JM acquired and analyzed the data, and wrote the manuscript. HN1 conceived the study and wrote the manuscript. SF, YT, HN2, YS, MS, SY, HT, and MD acquired and researched the data. AO, YF, SK, TF, NM, TN and IS reviewed the manuscript. All authors read and approved the final manuscript.

\begin{abstract}
Author details
${ }^{1}$ Department of Metabolic Medicine, Graduate School of Medicine, Osaka University, 2-2 B-5, Yamada-oka, Suita, Osaka 565-0871, Japan. ${ }^{2}$ Department of Diabetes and Endocrinology, Kawasaki Hospital Kobe, 3-3-1, Higashiyama-Cho, Hyogo-ku, Kobe 652-0042, Japan. ${ }^{3}$ Department of Adipose Management, Graduate School of Medicine, Osaka University, 2-2-B, Yamada-oka, Suita, Osaka 565-0871, Japan. ${ }^{4}$ Department of Metabolism and Atherosclerosis, Graduate School of Medicine, Osaka University, 2-2-B, Yamada-oka, Suita, Osaka 565-0871, Japan. ${ }^{5}$ Department of Gastroenterology, Kawasaki Hospital Kobe, 3-3-1, Higashiyama-Cho, Hyogo-ku, Kobe 652-0042, Japan. ${ }^{6}$ Department of Laboratory and Physiology, Kawasaki Hospital Kobe, 3-3-1, Higashiyama-Cho, Hyogo-ku, Kobe 652-0042, Japan.
\end{abstract}

\section{Acknowledgements}

We thank Dr. Mitsuyoshi Takahara (Osaka University), Dr. Morihiro Matsuda and Dr. Takahiro Kuwasako (Kawasaki Hospital) for the helpful discussion and suggestions.

\section{Competing interests}

The authors declare that they have no competing interests.

\section{Availability of data and materials}

The datasets used and/or analysed during the current study are available from the corresponding author on reasonable request.

\section{Consent for publication}

Not applicable.

\section{Ethics approval and consent to participate}

This study was approved by the Human Ethics Committees of Osaka University (No. 15061) and written informed consent was obtained from each subject after explaining the purpose and possible complications of the study.

\section{Funding}

This work was supported in part by Grants-in-Aid for Scientific Research (C) No. 15 K09412 (to HN), and No. 16 K09801 (to NM), Grants-in-Aid for Scientific Research (B) No. 15 H04853 (to IS), Pfizer Health Research Foundation (to HN), and MSDKK (Tokyo, Japan) (to HN).

\section{Publisher's Note}

Springer Nature remains neutral with regard to jurisdictional claims in published maps and institutional affiliations.

Received: 3 June 2018 Accepted: 28 July 2018

Published online: 04 August 2018

\section{References}

1. World Health Organization. Obesity and overweight. WHO Fact Sheet No. 311; 2014. http://www.wpro.who.int/mediacentre/factsheets/obesity/ en/. Accessed 1 Aug 2018.

2. Shaw JE, Sicree RA, Zimmet PZ. Global estimates of the prevalence of diabetes for 2010 and 2030. Diab Res Clin Pract. 2010;87:4-14.

3. Yoon $\mathrm{KH}$, Lee JH, Kim JW, Cho JH, Choi YH, Ko SH, Zimmet P, Son HY. Epidemic obesity and type 2 diabetes in Asia. Lancet. 2006;368:1681-8.

4. Chan JC, MalikV, Jia W, Kadowaki T, Yajnik CS, Yoon KH, Hu FB. Diabetes in Asia: epidemiology, risk factors, and pathophysiology. JAMA. 2009;301:2129-40.

5. Huxley R, James WP, Barzi F, Patel JV, Lear SA, Suriyawongpaisal P, Janus E, Caterson I, Zimmet P, Prabhakaran D, Reddy S, Woodward M, Obesity in
Asia Collaboration. Ethnic comparisons of the cross-sectional relationships between measures of body size with diabetes and hypertension. Obes Rev. 2008;9:53-61.

6. Han E, Lee YH, Lee BW, Kang ES, Lee IK, Cha BS. Anatomic fat depots and cardiovascular risk: a focus on the leg fat using nationwide surveys (KNHANES 2008-2011). Cardiovasc Diabetol. 2017;16:54.

7. Okauchi Y, Nishizawa H, Funahashi T, Ogawa T, Noguchi M, Ryo M, Kihara S, Iwahashi H, Yamagata K, Nakamura T, Shimomura I, Matsuzawa Y. Reduction of visceral fat is associated with decrease in the number of metabolic risk factors in Japanese men. Diab Care. 2007;30:2392-4.

8. Cruz-Jentoft AJ, Baeyens JP, Bauer JM, Boirie Y, Cederholm T, Landi F, Martin FC, Michel JP, Rolland Y, Schneider SM, Topinková E, Vandewoude M, Zamboni M, European Working Group on Sarcopenia in Older People. Sarcopenia: European consensus on definition and diagnosis: report of the European Working Group on Sarcopenia in Older People. Age Ageing. 2010;39:412-23.

9. Chen LK, Liu LK, Woo J, Assantachai P, Auyeung TW, Bahyah KS, Chou MY, Chen LY, Hsu PS, Krairit O, Lee JS, Lee WJ, Lee Y, Liang CK, Limpawattana P, Lin CS, Peng LN, Satake S, Suzuki T, Won CW, Wu CH, Wu SN, Zhang T, Zeng P, Akishita M, Arai H. Sarcopenia in Asia: consensus report of the Asian Working Group for Sarcopenia. J Am Med Dir Assoc. 2014;15:95-101.

10. Park SW, Goodpaster BH, Strotmeyer ES, Kuller LH, Broudeau R, Kammerer C, de Rekeneire N, Harris TB, Schwartz AV, Tylavsky FA, Cho YW, Newman $A B$, Health, Aging, and Body Composition Study. Accelerated loss of skeletal muscle strength in older adults with type 2 diabetes: the health, aging, and body composition study. Diab Care. 2007;30:1507-12.

11. Park SW, Goodpaster BH, Lee JS, Kuller LH, Boudreau R, de Rekeneire N, Harris TB, Kritchevsky S, Tylavsky FA, Nevitt M, Cho YW, Newman $A B$, Health, Aging, and Body Composition Study. Excessive loss of skeletal muscle mass in older adults with type 2 diabetes. Diab Care. 2009;32:1993-7.

12. Abbatecola AM, Ferrucci L, Ceda G, Russo CR, Lauretani F, Bandinelli S, Barbieri M, Valenti G, Paolisso G. Insulin resistance and muscle strength in older persons. J Gerontol A Biol Sci Med Sci. 2005;60:1278-82.

13. Wang T, Feng X, Zhou J, Gong H, Xia S, Wei Q, Hu X, Tao R, Li L, Qian F, Yu L. Type 2 diabetes mellitus is associated with increased risks of sarcopenia and pre-sarcopenia in Chinese elderly. Sci Rep. 2016;6:38937.

14. Leong DP, Teo KK, Rangarajan S, Lopez-Jaramillo P, Avezum A Jr, Orlandini A, Seron P, Ahmed SH, Rosengren A, Kelishadi R, Rahman O, Swaminathan S, labal R, Gupta R, Lear SA, Oguz A, Yusoff K, Zatonska K, Chifamba J, Igumbor E, Mohan V, Anjana RM, Gu H, Li W, Yusuf S, Prospective Urban Rural Epidemiology (PURE) Study investigators. Prognostic value of grip strength: findings from the Prospective Urban Rural Epidemiology (PURE) study. Lancet. 2015;386:266-73.

15. Lawman HG, Troiano RP, Perna FM, Wang CY, Fryar CD, Ogden CL. Associations of relative handgrip strength and cardiovascular disease biomarkers in U.S. adults, 2011-2012. Am J Prev Med. 2016;50:677-83.

16. World Health Organization. Definition and diagnosis of diabetes mellitus and intermediate hyperglycemia: report of a WHO/IDF consultation. Geneva: World Health Org; 2006.

17. Ryo M, Maeda K, Onda T, Katashima M, Okumiya A, Nishida M, Yamaguchi T, Funahashi T, Matsuzawa Y, Nakamura T, Shimomura I. A new simple method for the measurement of visceral fat accumulation by bioelectrical impedance. Diab Care. 2005;28:451-3.

18. Malavolti M, Mussi C, Poli M, Fantuzzi AL, Salvioli G, Battistini N, Bedogni G. Cross-calibration of eight-polar bioelectrical impedance analysis versus dual-energy $X$-ray absorptiometry for the assessment of total and appendicular body composition in healthy subjects aged 21-82 years. Ann Hum Biol. 2003:30:380-91.

19. Park SW, Goodpaster BH, Strotmeyer ES, de Rekeneire N, Harris TB, Schwartz AV, Tylavsky FA, Newman AB. Decreased muscle strength and quality in older adults with type 2 diabetes: the health, aging, and body composition study. Diabetes. 2006;55:1813-8.

20. Japanese Society of Nephrology. Evidence-based practice guideline for the treatment of CKD. Clin Exp Nephrol. 2009;13:537-66.

21. Arita Y, Kihara S, Ouchi N, Takahashi M, Maeda K, Miyagawa J, Hotta K, Shimomura I, Nakamura T, Miyaoka K, Kuriyama H, Nishida M, Yamashita S, Okubo K, Matsubara K, Muraguchi M, Ohmoto Y, Funahashi T, Matsuzawa Y. Paradoxical decrease of an adipose-specific protein, adiponectin, in obesity. Biochem Biophys Res Commun. 1999;257:79-83. 
22. Hirata A, Kishida K, Hiuge-Shimizu A, Nakatsuji H, Funahashi T, Shimomura I. Qualitative score of systemic arteriosclerosis by vascular ultrasonography as a predictor of coronary artery disease in type 2 diabetes. Atherosclerosis. 2011;219:623-9.

23. Katakami N, Matsuhisa M, Kaneto H, Matsuoka TA, Sakamoto K, Yasuda T, Umayahara Y, Kosugi K, Yamasaki Y. Serum endogenous secretory RAGE level is an independent risk factor for the progression of carotid atherosclerosis in type 1 diabetes. Atherosclerosis. 2009;204:288-92.

24. Jablecki CK, Andary MT, Floeter MK, Miller RG, Quartly CA, Vennix MJ, Wilson JR, American Association of Electrodiagnostic Medicine; American Academy of Neurology; American Academy of Physical Medicine and Rehabilitation. Practice parameter: Electrodiagnostic studies in carpal tunnel syndrome. Report of the American Association of Electrodiagnostic Medicine, American Academy of Neurology, and the American Academy of Physical Medicine and Rehabilitation. Neurology. 2002;58:1589-92.

25. Falck B, Stålberg E. Motor nerve conduction studies: measurement principles and interpretation of findings. J Clin Neurophysiol. 1995;12:254-79.

26. Examination Committee of Criteria for 'Obesity Disease' in Japan, Japan Society for the Study of Obesity. New criteria for 'obesity disease' in Japan. Circ J. 2002;66:987-92.

27. Després JP, Lamarche B. Effects of diet and physical activity on adiposity and body fat distribution: implications for the prevention of cardiovascular disease. Nutr Res Rev. 1993;6:137-59.

28. Yamanaka H, Japanese Society of Gout and Nucleic Acid Metabolism Japanese guideline for the management of hyperuricemia and gout: second edition. Nucleosides Nucleotides Nucleic Acids. 2011;30:1018-29.

29. Hernaez R, Lazo M. Bonekamp, Kamel I, Brancati FL, Guallar, Clark JM. Diagnostic accuracy and reliability of ultrasonography for the detection of fatty liver: a meta-analysis. Hepatology. 2011;54:1082-90.

30. Hiatt WR. Medical treatment of peripheral arterial disease and claudication. N Engl J Med. 2001;344:1608-21.

31. Mohler ER 3rd. Peripheral arterial disease: identification and implications. Arch Intern Med. 2003;163:2306-14.

32. Cruz-Jentoft AJ, Landi F, Schneider SM, Zúñiga C, Arai H, Boirie Y, Chen LK, Fielding RA, Martin FC, Michel JP, Sieber C, Stout JR, Studenski SA, Vellas B, Woo J, Zamboni M, Cederholm T. Prevalence of and interventions for sarcopenia in ageing adults: a systematic review. Report of the International Sarcopenia Initiative (EWGSOP and IWGS). Age Ageing. 2014;43:748-59.

33. Yoshida D, Suzuki T, Shimada H, Park H, Makizako H, Doi T, Anan Y, Tsutsumimoto K, Uemura K, Ito T, Lee S. Using two different algorithms to determine the prevalence of sarcopenia. Geriatr Gerontol Int. 2014;14:46-51.

34. Yoshimura N, Muraki S, Oka H, lidaka T, Kodama R, Kawaguchi H, Nakamura K, Tanaka S, Akune T. Is osteoporosis a predictor for future sarcopenia or vice versa? Four-year observations between the second and third ROAD study surveys. Osteoporos Int. 2017;28:189-99.

35. Anbalagan VP, Venkataraman V, Pradeepa R, Deepa M, Anjana RM, Mohan $\mathrm{V}$. The prevalence of presarcopenia in Asian Indian individuals with and without type 2 diabetes. Diab Technol Ther. 2013;15:768-75.

36. Leenders M, Verdijk LB, van der Hoeven L, Adam JJ, van Kranenburg J, Nilwik $R$, van Loon LJ. Patients with type 2 diabetes show a greater decline in muscle mass, muscle strength, and functional capacity with aging. J Am Med Dir Assoc. 2013;14:585-92.

37. Rossi AP, Bianchi L, Volpato S, Bandinelli S, Guralnik J, Zamboni M, Ferrucci L. Dynapenic abdominal obesity as a predictor of worsening disability, hospitalization, and mortality in older adults: results from the InCHIANTI Study. J Gerontol A Biol Sci Med Sci. 2017;72:1098-104.

38. Ali S, Garcia JM. Sarcopenia, cachexia and aging: diagnosis, mechanisms and therapeutic options-a mini-review. Gerontology. 2014;60:294-305.

39. Andersen H, Stålberg E, Gjerstad MD, Jakobsen J. Association of muscle strength and electrophysiological measures of reinnervation in diabetic neuropathy. Muscle Nerve. 1998;21:1647-54
40. Matsuzawa Y, Funahashi T, Nakamura T. The concept of metabolic syndrome: contribution of visceral fat accumulation and its molecular mechanism. J Atheroscler Thromb. 2011;18:629-39.

41. Bouchi R, Ohara N, Asakawa M, Nakano Y, Takeuchi T, Murakami M, Sasahara Y, Numasawa M, Minami I, Izumiyama H, Hashimoto K, Yoshimoto T, Ogawa Y. Is visceral adiposity a modifier for the impact of blood pressure on arterial stiffness and albuminuria in patients with type 2 diabetes? Cardiovasc Diabetol. 2016;15:10.

42. Tamba S, Nakatsuji H, Kishida K, Noguchi M, Ogawa T, Okauchi Y, Nishizawa H, Imagawa A, Nakamura T, Matsuzawa Y, Funahashi T, Shimomura I. Relationship between visceral fat accumulation and urinary albumin-creatinine ratio in middle-aged Japanese men. Atherosclerosis. 2010;211:601-5.

43. Tanaka Kl, Kanazawa I, Sugimoto T. Reduced muscle mass and accumulation of visceral fat are independently associated with increased arterial stiffness in postmenopausal women with type 2 diabetes mellitus. Diab Res Clin Pract. 2016;122:141-7.

44. Kusminski CM, Bickel PE, Scherer PE. Targeting adipose tissue in the treatment of obesity-associated diabetes. Nat Rev Drug Discov. 2016;15:639-60.

45. Visser M, Pahor M, Taaffe DR, Goodpaster BH, Simonsick EM, Newman AB, Nevitt M, Harris TB. Relationship of interleukin- 6 and tumor necrosis factor-alpha with muscle mass and muscle strength in elderly men and women: the Health ABC Study. J Gerontol A Biol Sci Med Sci. 2002;57:M326-32.

46. Taaffe DR, Harris TB, Ferrucci L, Rowe J, Seeman TE. Cross-sectional and prospective relationships of interleukin-6 and C-reactive protein with physical performance in elderly persons: MacArthur studies of successful aging. J Gerontol A Biol Sci Med Sci. 2000;55:M709-15.

47. Schrager MA, Metter EJ, Simonsick E, Ble A, Bandinelli S, Lauretani F, Ferrucci L. Sarcopenic obesity and inflammation in the InCHIANTI study. J Appl Physiol. 2007;102:919-25.

48. Obata Y, Maeda N, Yamada Y, Yamamoto K, Nakamura S, Yamaoka M, Tanaka Y, Masuda S, Nagao H, Fukuda S, Fujishima Y, Kita S, Nishizawa H, Funahashi T, Matsubara K, Matsuzawa Y, Shimomura I. Impact of visceral fat on gene expression profile in peripheral blood cells in obese Japanese subjects. Cardiovasc Diabetol. 2016;15:159.

49. Hwang YC, Jeon WS, Park CY, Youn BS. The ratio of skeletal muscle mass to visceral fat area is a main determinant linking circulating irisin to metabolic phenotype. Cardiovasc Diabetol. 2016;15:9.

50. Matsuda K, Fujishima Y, Maeda N, Mori T, Hirata A, Sekimoto R, Tsushima Y, Masuda S, Yamaoka M, Inoue K, Nishizawa H, Kita S, Ranscht B, Funahashi T, Shimomura I. Positive feedback regulation between adiponectin and T-cadherin impacts adiponectin levels in tissue and plasma of male mice. Endocrinology. 2015;156:934-46.

51. Maeda N, Shimomura I, Kishida K, Nishizawa H, Matsuda M, Nagaretani $\mathrm{H}$, Furuyama N, Kondo H, Takahashi M, Arita Y, Komuro R, Ouchi N, Kihara S, Tochino Y, Okutomi K, Horie M, Takeda S, Aoyama T, Funahashi T, Matsuzawa Y. Diet-induced insulin resistance in mice lacking adiponectin/ ACRP30. Nat Med. 2002;8:731-7.

52. Celis-Morales CA, Petermann F, Hui L, Lyall DM, Iliodromiti S, McLaren J, Anderson J, Welsh P, Mackay DF, Pell JP, Sattar N, Gill JMR, Gray SR. Associations between diabetes and both cardiovascular disease and all-cause mortality are modified by grip strength: evidence from UK biobank, a prospective population-based cohort study. Diab Care. 2017:40:1710-8.

53. Tuzun S, Oner C, Dabak MR, Kasikci HO, Sargin M. Relation of muscle indices with metabolic parameters and C-peptide in type 2 diabetes mellitus. J Coll Physicians Surg Pak. 2017;27:673-7.

54. Bouchi R, Fukuda T, Takeuchi T, Nakano Y, Murakami M, Minami I, Izumiyama H, Hashimoto K, Yoshimoto T, Ogawa Y. Dipeptidyl peptidase 4 inhibitors attenuates the decline of skeletal muscle mass in patients with type 2 diabetes. Diab Metab Res Rev. 2018. https://doi.org/10.1002/ dmrr.2957. 